\title{
A COMPARATIVE STUDY OF LAND SURFACE TEMPERATURE WITH DIFFERENT INDICES ON HETEROGENEOUS LAND COVER USING LANDSAT 8 DATA
}

\author{
Ruchi Bala ${ }^{1, *}$, Rajendra Prasad ${ }^{1}$, Vijay Pratap Yadav ${ }^{1}$, Jyoti Sharma $^{1}$ \\ ${ }^{1}$ Department of Physics, Indian Institute of Technology (BHU), Varanasi - ruchibala7@gmail.com, rprasad.app@itbhu.ac.in, \\ victory327759@gmail.com, jyotisharma.rs.phy17@itbhu.ac.in
}

Commission V, SS: Disaster Monitoring, Damage Assessment and Risk Reduction

KEY WORDS: LST, Landsat 8, NDBI, NDSI, NDVI, NDWI, Land Cover

\begin{abstract}
:
The temperature rise in urban areas has become a major environmental concern. Hence, the study of Land surface temperature (LST) in urban areas is important to understand the behaviour of different land covers on temperature. Relation of LST with different indices is required to study LST in urban areas using satellite data. The present study focuses on the relation of LST with the selected indices based on different land cover using Landsat 8 OLI (Operational Land Imager) and TIRS (Thermal Infrared Sensor) data in Varanasi, India. A regression analysis was done between LST and Normalized Difference Vegetation index (NDVI), Normalized Difference Soil Index (NDSI), Normalized Difference Built-up Index (NDBI) and Normalized Difference Water Index (NDWI). The non-linear relations of LST with NDVI and NDWI were observed, whereas NDBI and NDSI were found to show positive linear relation with LST. The correlation of LST with NDSI was found better than NDBI. Further analysis was done by choosing 25 pure pixels from each land cover of water, vegetation, bare soil and urban areas to determine the behaviour of indices on LST for each land cover. The investigation shows that NDSI and NDBI can be effectively used for study of LST in urban areas. However, NDBI can explain urban LST in the better way for the regions without water body.
\end{abstract}

\section{INTRODUCTION}

Urban Heat Island (UHI) refers to the urban areas which has temperatures higher than the surrounding suburban or rural areas due to increase in urbanization. Urbanization has led to the replacement of natural land covers with the artificial built up surfaces made up of impervious materials and decrease of vegetation which helps in reducing temperatures due to evapotranspiration (Voogt and Oke, 2003). Various previous studies have shown that bare soil and built up areas have higher temperatures whereas waterbodies and vegetated land have lower temperatures (Song et al. 2014). The study of LST of urban areas and also different land covers has become important for the requirement of sustainable planning and environmental protection. The factors responsible for resultant temperature rise must be identified in order to attenuate the UHI effect (Kaufmann et al. 2007, Mountrakis and Luo. 2011).

Thermal bands in remote sensing satellite are the most important source for determining LST. Various satellites contain thermal bands like Landsat, Aster, AVHRR, MODIS etc. Fine spatial resolution is required for the study of LST variation in urban areas due to greater heterogeneity in urban areas. Landsat and Aster data has been widely used for study of UHI effect in urban areas due to its fine spatial resolution (Tsou et al. 2017, Yu et al. 2014).

Various scholars have studied on the correlation between LST and some land use (LU) /land cover (LC) indices for different study area and found that the correlation of LST with LU-LC indices was different (Deilami and Kamruzzaman, 2017; Ma et al. 2016, Mathew et al. 2016, Nie et al. 2016, Tran. et al. 2017). So, this study focuses on the relation of LST with the selected indices i.e. NDVI, NDBI, NDSI and NDWI based on different land cover using Landsat 8 data in Varanasi, India. In order to understand the relation, 25 pure pixels for each land cover of water, vegetation, bare soil and urban areas were chosen to determine behaviour of LST and indices with the land covers.

\section{STUDY AREA}

The study area, Varanasi city, is a very old city located at the banks of River Ganges in the Eastern part of the state of Uttar Pradesh, North India. The city lies at the coordinates $25.28{ }^{0} \mathrm{~N}$ and $82.96{ }^{\circ} \mathrm{E}$ at an elevation of 80.71 meters and covers an area of $82.10 \mathrm{~km}^{2}$. Varanasi experiences a humid subtropical climate. Location map of study area is shown in Figure 1.

\footnotetext{
${ }^{*}$ Corresponding author
} 


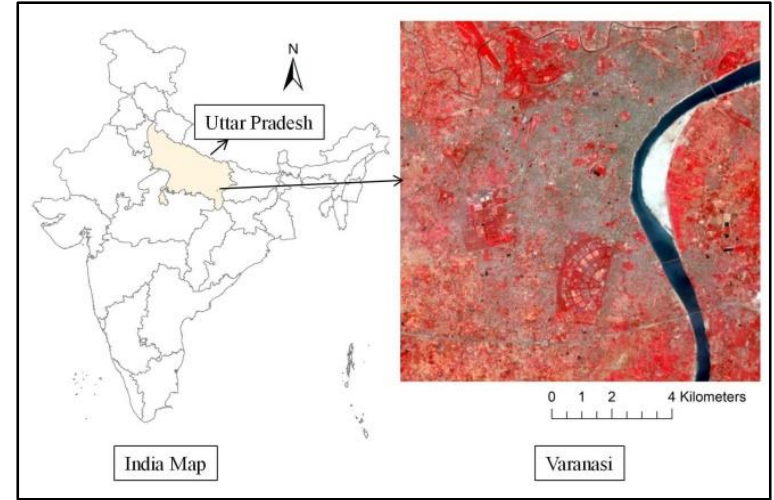

Figure1. Location map of study area

This image of Varanasi is the false color composite image obtained from Landsat data. The city was chosen for this study due to the availability of land covers like waterbody, urban areas, bare soil region as well as vegetated land covering sufficient area which makes this useful to study the behaviour of each land cover.

\section{DATA USED AND IMAGE PRE- PROCESSING}

Landsat satellite images were generated and distributed by the U.S. Geological Survey (USGS) since 1972. Landsat level 1 data products are geometric, radiometric and terrain corrected. Landsat 8 images contain 11 bands of which band 10 and 11 are thermal bands. The Landsat 8 images have $30 \mathrm{~m}$ spatial, 12 bit radiometric and 16 days temporal resolution. The spatial resolution of thermal bands is 100 $\mathrm{m}$, and is resampled to $30 \mathrm{~m}$ for distribution.

Landsat 8 images were downloaded from the USGS website i.e. https://earthexplorer.usgs.gov/ of the date 10/04/2017 (Path 142/ Row 42) for day time. The Varanasi region was clipped from the image for the study. The original Digital numbers of OLI images were converted to reflectance using methods provided by Landsat 8 Data user Handbook (2016).

\section{METHODOLOGY}

\subsection{Calculation of Indices}

The indices used in the study were obtained from the visible, Near Infra-Red and Short Wave Infra-Red reflectance bands from the Landsat satellite data. The index maps were obtained using the equations as shown in Table1.

\begin{tabular}{|c|c|}
\hline Indices & Equations \\
\hline $\begin{array}{c}\text { Normalized Difference } \\
\text { Vegetation Index (NDVI) }\end{array}$ & $\frac{N I R-R E D}{N I R+R E D}$ \\
\hline $\begin{array}{c}\text { Normalized Difference Built- } \\
\text { up Index (NDBI) }\end{array}$ & $\frac{S W I R_{1}-N I R}{S W I R_{1}+N I R}$ \\
\hline $\begin{array}{c}\text { Normalized Difference Soil } \\
\text { Index (NDSI) }\end{array}$ & $\frac{S W I R_{2}-G R E E N}{S W I R_{2}+G R E E N}$ \\
\hline $\begin{array}{c}\text { Normalized Difference } \\
\text { Water Index (NDWI) }\end{array}$ & $\frac{G R E E N-N I R}{G R E E N+N I R}$ \\
\hline
\end{tabular}

Table1. Equations for estimating different Indices

\subsection{Calculation of LST}

Thermal band (band10) of Landsat 8 images was used for determining LST image. Various steps are involved in the estimation of LST from Landsat image (Essa et al. 2012). The digital number of thermal band was first rescaled into Top of atmosphere radiance (TOA) using Equation (1).

$$
L_{\lambda}=M_{L} \times(D N)+A_{L}
$$

where $\mathrm{M}_{\mathrm{L}}=$ multiplicative rescaling factor

$\mathrm{A}_{\mathrm{L}}=$ additive rescaling factor

$\mathrm{DN}=$ digital number of thermal band.

The TOA radiance includes a mixed signal that contains emission from land as well as atmosphere. Hence, atmospheric correction was performed to eliminate the contribution from the atmosphere. Therefore, TOA radiance was converted into surface leaving radiance $\left(\mathrm{L}_{\mathrm{T}}\right)$ using Equation (2).

$$
L_{T}=\frac{\left(L_{\lambda}\right)-L_{\mu}-\tau \times(1-\varepsilon) \times L_{d}}{\tau \times \varepsilon}
$$

where $\mathrm{L}_{\mu}=$ upwelling radiance

$$
\begin{aligned}
& \mathrm{L}_{\mathrm{d}}=\text { downwelling radiance } \\
& \tau=\text { transmission } \\
& \varepsilon=\text { emissivity }
\end{aligned}
$$

The atmospheric parameters like transmission $(\tau)$, upwelling radiance $\left(\mathrm{L}_{\mu}\right)$ and downwelling radiances $\left(\mathrm{L}_{\mathrm{d}}\right)$ values were obtained from an atmospheric correction tool available at http://atmcorr.gsfc.nasa.gov/ only for Landsat 4-5, 7 and 8 satellite images developed by Barsi et al. (2005) and the emissivity values were estimated using NDVI (Van de Griend and Owe, 1993) as shown in the Table (2). 


\begin{tabular}{|c|c|}
\hline NDVI & Land surface emissivity \\
\hline NDVI $<-0.185$ & 0.995 \\
\hline$-0.185<$ NDVI $<0.157$ & 0.970 \\
\hline $0.157<$ NDVI $<0.727$ & $1.0094+0.047 \ln (\mathrm{NDVI})$ \\
\hline NDVI $>0.727$ & 0.990 \\
\hline
\end{tabular}

Table 2. Land Surface Emissivity estimation from NDVI

Then, the surface leaving radiance was converted into LST using Planck's law as given in Equation (3)

$$
T_{s}=\frac{K_{2}}{\ln \left(1+\frac{K_{1}}{\left(L_{T}\right)}\right)}
$$

where $\quad \mathrm{K}_{1}, \mathrm{~K}_{2}=$ thermal constants

$\mathrm{T}_{\mathrm{s}}=$ Land Surface Temperature.

\section{RESULTS AND DISCUSSIONS}

In order to study the behaviour of LST in the city, the LST image was generated as shown in Figure 2. It was observed that the River Ganges show very low LST, the dry sandy area at the bank of River Ganga shows very high LST. The urban areas of the city show LST higher than the vegetated areas and waterbody but lower than the bare soil or dry sandy areas.

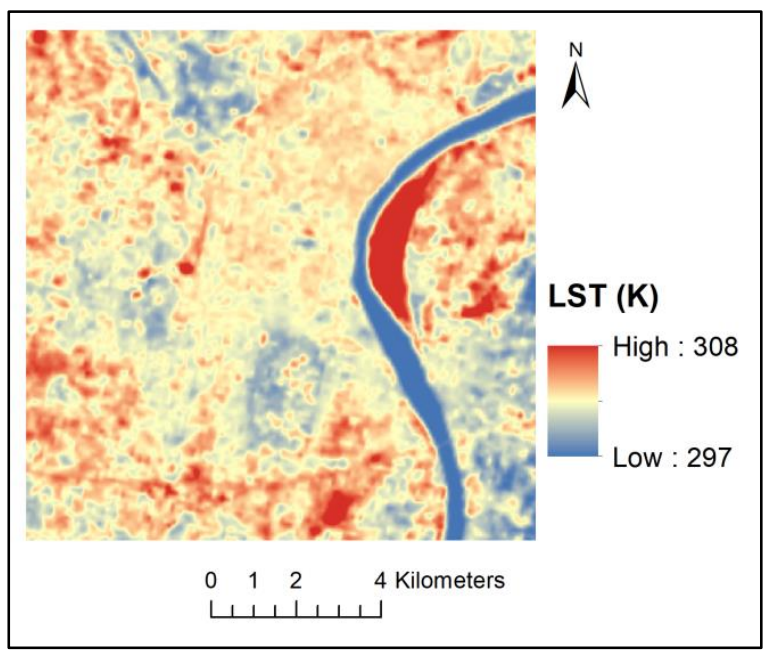

Figure2. LST image of Varanasi

In order to study the relation of LST with the respective indices, scatter plots were obtained for LST with NDVI, NDBI, NDSI and NDWI and are shown in Figures $3-6$ respectively.

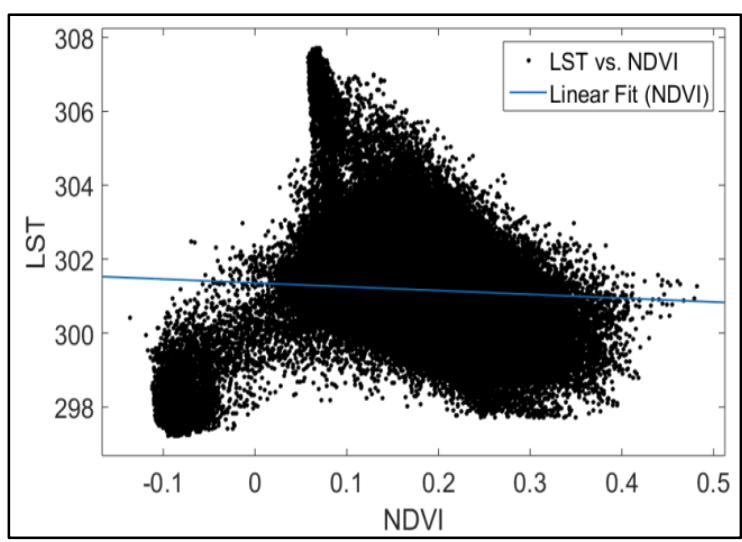

Figure 3.Scatter plot of LST with NDVI

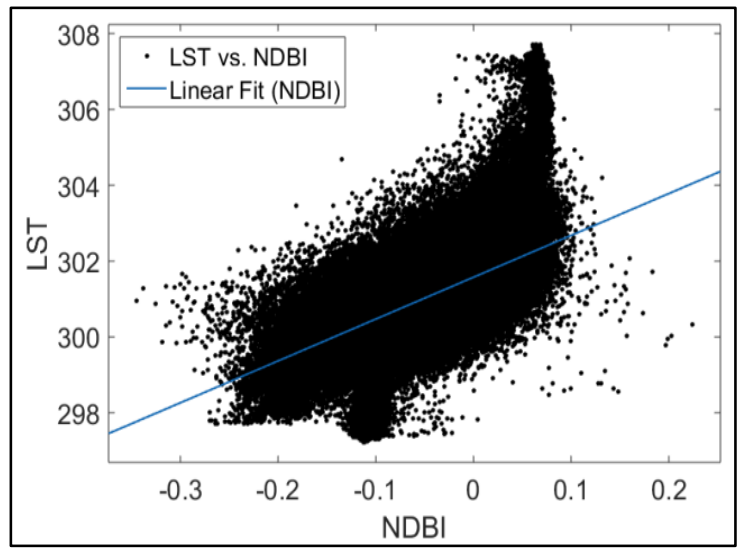

Figure 4.Scatter plot of LST with NDBI

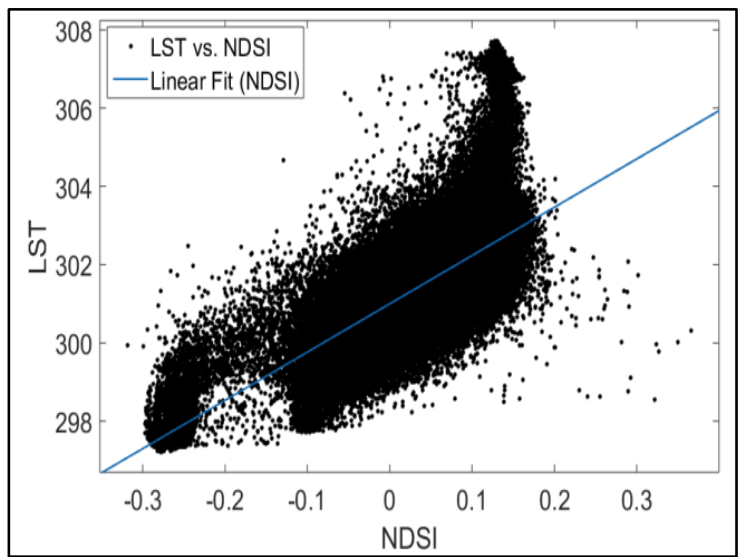

Figure 5.Scatter plot of LST with NDSI 


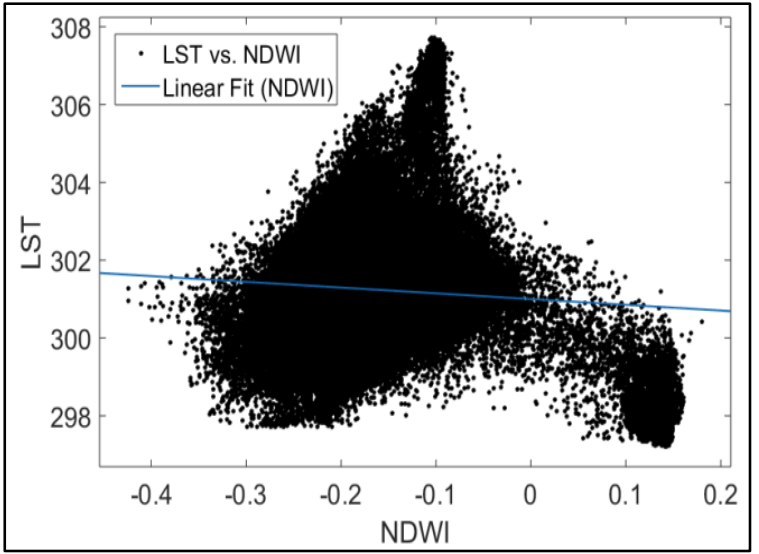

Figure 6.Scatter plot of LST with NDWI

\begin{tabular}{|c|c|c|c|c|}
\hline Indices & Slope & Intercept & R-square & RMSE \\
\hline NDVI & -1.029 & 301.4 & 0.2912 & 1.103 \\
\hline NDBI & 11.04 & 301.6 & 0.5815 & 0.8474 \\
\hline NDSI & 12.35 & 301.0 & 0.7251 & 0.6868 \\
\hline NDWI & -1.476 & 301.0 & 0.3137 & 0.9503 \\
\hline
\end{tabular}

Table3. Regression parameters for LST relation with indices

It was observed from the scatterplot that NDVI and NDWI shows non-linear relation but NDBI and NDSI shows positive linear relation with LST. The regression parameters obtained from the relation of LST with indices are shown in Table 3. The correlation of NDVI and NDWI was found very low and that of NDBI and NDSI was higher. Different land covers have different behaviour towards LST as well as indices. Waterbodies and vegetation shows lower LST whereas built up and bare soil region shows higher LST during day time (Amiri et al. 2009). The relation of LST with different LU-LC indices depends on the type of land cover present in the region. So for further analysis, 25 pure pixels were chosen for each land cover of vegetation, water, urban and vegetated areas. Then, the relation of LST with the indices was determined for these pure pixels to understand the behaviour of different land cover. The relation of LST with NDVI, NDBI, NDSI and NDWI based on each land cover obtained are shown in Figures $7-10$ respectively.

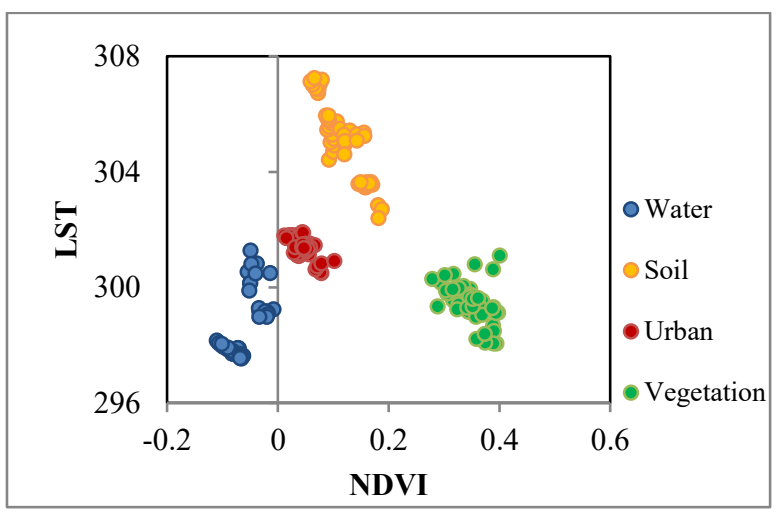

Figure7. LST-NDVI relation with land cover

Waterbodies has lower LST but shows negative values of NDVI and other land covers shows positive values. The vegetative land covers shows higher positive values than bare soil and urban regions but lower LST values. This explains the non-linear behaviour of LST with NDVI. Since, urban areas also include soil, vegetation and water, NDVI cannot explain LST in urban regions due to greater heterogeneity in land cover. But agricultural region contains only bare soil and vegetation, so NDVI can explain LST better in agricultural regions.

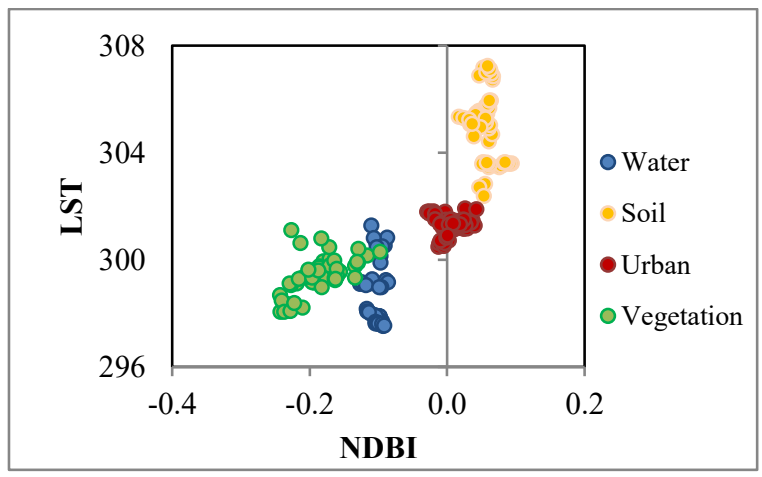

Figure8. LST-NDBI relation with land cover

Negative values of NDBI shows waterbodies as well as vegetation which shows lower LST values and higher LST land covers i.e. urban and bare soil regions shows NDBI values nearby or greater than zero. This explains the linear relation of LST with NDBI. Hence, NDBI can be used to study LST in region containing heterogeneous land covers. 


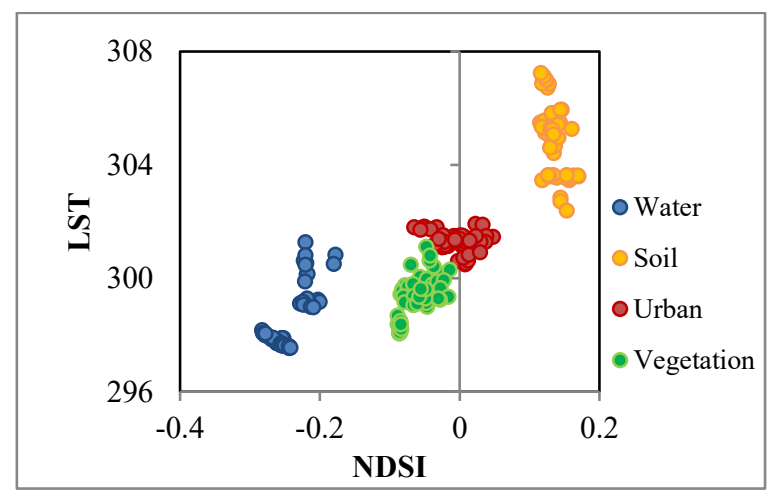

Figure9. LST-NDSI relation with land cover

Waterbodies shows very low negative values for NDSI whereas bare soil shows very high positive NDSI values. Urban areas have NDSI values near to zero with positive as well as negative values of NDSI. Vegetation shows negative values of NDSI near to zero. This explains linear relation of LST with NDSI.

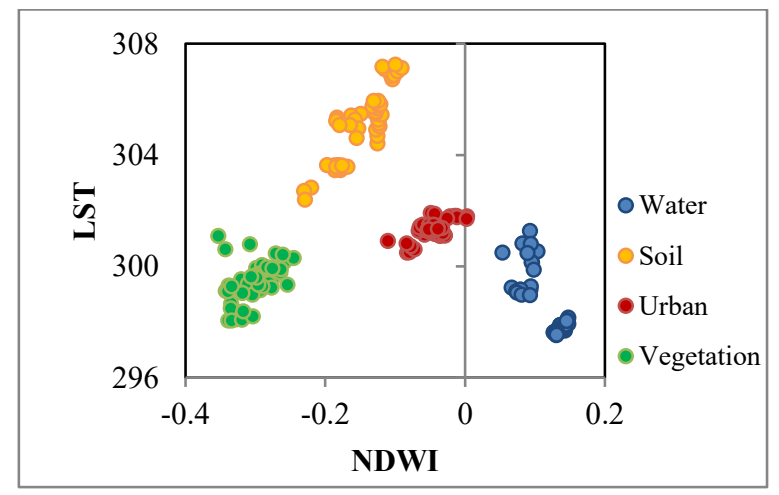

Figure10. LST-NDWI relation with land cover

Waterbodies shows positive values of NDWI with lower LST whereas other land covers shows negative values. Vegetated pixels shows very low negative values but also lower LST. This explains the non-linear behaviour of LST with NDWI. Hence, NDWI cannot be used in study of LST in urban areas. NDWI can explain LST in those urban areas with no vegetation cover because bare soil, urban and water has linear relation of LST with NDWI.

The nonlinear relation of LST with NDVI and NDWI was observed because the NDVI and NDWI values of higher LST pixels i.e. urban and bare soil lies between two lower LST pixels i.e. vegetation and waterbodies. Hence, NDVI and NDWI are found not suitable for study of LST in heterogeneous land cover. The positive linear relation of LST with NDBI and NDSI was observed because the land covers with positive NDBI and NDSI values shows higher LST whereas those with negative NDBI and NDSI values shows lower LST. The correlation was found greater for NDSI than NDBI. In case of NDBI, water pixels shows higher NDBI than vegetated pixels but LST is lower for water pixels than vegetated pixels which results in lower R- square. In case of NDSI, water, vegetation, soil as well as urban pixels shows positive relation with LST making it more suitable for study of LST in urban areas. NDBI can also explain urban LST better in regions without water body.

\section{CONCLUSIONS}

The study focuses on the relation of LST with the selected indices i.e. NDVI, NDBI, NDSI and NDWI using Landsat 8 OLI and TIRS data. A regression analysis was done between LST and the selected indices. The non-linear relations of LST with NDVI and NDWI were observed, whereas NDBI and NDSI were found to show positive linear relation with LST. The correlation of LST with NDSI was found better than NDBI. Further analysis was done by choosing 25 pure pixels from each land cover of water, vegetation, bare soil and urban areas and plotted to determine the behaviour of indices on LST for each land cover. The investigation shows that NDSI and NDBI can be effectively used for study of LST in urban areas. However, NDBI can explain urban LST in the better way for the regions without water body.

\section{ACKNOWLEDGEMENT}

The authors are thankful to the Council of Scientific and Industrial Research (CSIR), New Delhi for providing financial support and also the National Aeronautics and Space Administration (NASA) for providing free access to the satellite data used in the present study.

\section{REFERENCES}

Amiri, R., Weng, Q., Alimohammadi, A., \& Alavipanah, S. K. (2009). Spatial-temporal dynamics of land surface temperature in relation to fractional vegetation cover and land use/cover in the Tabriz urban area, Iran. Remote Sensing of Environment, 113, 2606-2617.

Barsi J. A., Schott J. R., Palluconi F. D., \& Hook S. J. (2005). Validation of a web based atmospheric correction tool for single thermal band instruments. Proceedings, SPIE, vol. 5882. Paper 58820E. Bellingham, WA. 7 pp.

Deilami, K., \& Kamruzzaman, M. (2017). Modelling the urban heat island effect of smart growth policy scenarios in Brisbane. Land Use Policy, 64, 38-55.

Essa, W., B. Verbeiren, J. Van Der Kwast, T. Van De Voorde, and O. Batelaan. 2012. "Evaluation of the Distrad Thermal Sharpening Methodology for Urban Areas." International Journal of Applied Earth Observation and Geoinformation 19: 163-172.

Kauffman, R. K., K. C. Seto, A. Schneider, Z. Liu, L. Zhou, and W. Wang. 2007. "Climate response to rapid urban growth: evidence of a human-induced precipitation deficit." Journal of Climate 20: 2299-2306. 
Landsat 8 Data Users Handbook (2016). URL: https://landsat.usgs.gov/landsat-8-data-users-handbook, National Aeronautics and Space Administration.

Ma, Q., Wu, J., \& He, C. (2016). A hierarchical analysis of the relationship between urban impervious surfaces and land surface temperatures: Spatial scale dependence, temporal variations, and bioclimatic modulation. Landscape Ecology, 31, 1139-1153.

Mathew, A., Sreekumar, S., Khandelwal, S., Kaul, N., \& Kumar, R. (2016). Prediction of surface temperatures for the assessment of urban heat island effect over Ahmedabad city using linear time series model. Energy and Buildings, $128,605-616$.

Mountrakis G., Luo L. (2011). Enhancing and replacing spectral information with intermediate structural inputs: a case study on impervious surface detection. Remote Sensing of Environment, 115, 1162-1170.

Nie, Q., Man, W., Li, Z., \& Huang, Y. (2016). Spatiotemporal impact of urban impervious surface on land surface temperature in Shanghai, China. Canadian Journal of Remote Sensing, 42(6), 680-689.

Song, J., Du, S., Feng, X., \& Guo, L. (2014). The relationships between landscape compositions and land surface temperature: Quantifying their resolution sensitivity with spatial regression models. Landscape and Urban Planning, 123, 145-157.

Tran., D.X., Pla, F., Carmona, P.L., Myint, S.W., Caetano, M., \& Kieua, P.V. (2017). Characterizing the relationship between land use land cover change and land surface temperature. ISPRS Journal of Photogrammetry and Remote Sensing, 124, 119-132.

Tsou J., Zhuang J., Li Y., Zhang Y. (2017). Urban Heat Island Assessment Using the Landsat 8 Data: A Case Study in Shenzhen and Hong Kong. Urban Science, 1,10.

Van de Griend, A. A., and M. Owe. 1993. "On the relationship between thermal emissivity and the normalized difference vegetation index for natural surfaces." International Journal of Remote Sensing 14: 1119-1131.

Voogt, J. A., T. R. Oke. 2003. "Thermal remote sensing of urban areas." Remote sensing of Environment 86: 370-384.

Yu X., Guo X., Wu Z. (2014). Land Surface Temperature Retrieval from Landsat 8 TIRS-Comparison between Radiative Transfer Equation-Based Method, Split Window Algorithm and Single Channel Method. Remote Sensing, 6, 9829-9852. 